\title{
Possible Otrivine-Induced Brutal Bilateral Exsudative Retinal Detachment
}

\author{
Miray Louis de Gonzague \\ Ophtalmology service of Universitary Hospital \\ Tambohobe Fianarantsoa Madagascar
}

Ramilitiana Benja

Nephrology service of Universitary Hospital Joseph Raseta

Befelatanana Antananarivo Madagascar

Raharimanantsoa Onja Lalaina

Ophtalmology service of Universitary Hospital Joseph Ravoahangy

Andrianavalona Antananarivo Madagascar

Raobela Léa

Ophtalmology service of Universitary Hospital Joseph Ravoahangy

Andrianavalona Antananarivo Madagascar

\begin{abstract}
Retinal detachment (RD) is the separation of the neurosensory retina (NSR) from the underlying retinal pigment epithelium (RPE). The purpose is to report a case of patiente presenting a brutal bilateral exsudative retinal detachment. A 25-year-old woman with no significant ocular history noted rapid, painless blurring in both eyes, facial edema and buccal dryness 2 days following a nasal spray of Otrivine by selfmedication for nasal stuffiness. Her best-corrected visual acuity was hand movement perception in both eyes. The anterior chamber, iris, and intraocular pressures were within normal limits. Dilated fundus examination showed clear vitreous with intraretinal hard exsudats mimicking an hypertensive retinopathy and inferior retinal detachment in both eyes. We suspected a drug-induced retinal detachment. We ask several experts for their opinion toward this case. Physicians should enquire about the overuse of nasal sprays.They must monitor patients' use of nasal sprays containing oxymetazoline and advise those with chronic nasal congestion that the overuse of this drug may be dangerous.
\end{abstract}

Keywords: Corticosteroid, Otrivine, Retinal detachment, Vasoconstrictor.

\section{INTRODUCTION}

Retinal detachment (RD) is the separation of the neurosensory retina (NSR) from the underlying retinal pigment epithelium (RPE) [1]. There are 3 types of retinal detachment: Rhegmatogenous RD, Exudative (or serous) RD and Tractional RD.

Rhegmatogenous $\mathrm{RD}$ in most cases, $\mathrm{RD}$ is usually resulting from age-related degenerative liquefaction and shrinkage of the vitreous. Exudative (or serous) RD results from the accumulation of serous and/or haemorrhagic fluid in the subretinal space because of hydrostatic factors (eg, severe acute hypertension), inflammation (eg, sarcoid uveitis), or neoplastic effusions. Exudative RD generally resolves with successful treatment of the underlying disease. Visual recovery is often excellent. Tractional RD: occurs via mechanical 
forces on the retina, usually mediated by fibrotic tissue resulting from previous haemorrhage, injury, surgery, infection, or inflammation [2][3].

The purpose is to report a case of female patiente presenting a brutal bilateral exsudative retinal detachment.

\section{OBSERVATION}

A 25-year-old woman with no significant ocular history was referred for evaluation of brutal vision loss in both eyes on Mey 2019. She was taken to consultation by her mother who is a witchcraft believer. The patient noted rapid, painless blurring in both eyes, swelling face (Figure 1) and buccal dryness 2 days following a nasal spray of Otrivine by selfmedication for nasal stuffiness 6 times a day. She has been treated at nephrology service of Befelatanana universtirary hospital Antananarivo Madagascar for chronic kidney failure following a stenosis of artery of the kidney complicating a Takayasu disease. She was treated with oral Corticosteroid, Aspegic and antihypertensive drugs. She repported a past history of allergic rhinitis with Otrivine spray, allergic to Penicillin, a high blood pressure and she underwent an appendicectomy in 2012. She is nulliparous. Her mother told us that her daughter might have gotten some poisonous food from their neighbour. On examination, she complained of having a terrible headach, her blood pressure was 195/75 mmHg, pulse was 115 beats per minute, and temperature was $37^{\circ} \mathrm{C}$.She presented a swelling of the face and lips. Her best-corrected visual acuity was hand movement perception in both eyes. The anterior chamber, iris, and intraocular pressures were within normal limits. Dilated fundus examination showed clear vitreous with intraretinal hard exsudats mimicking an hypertensive retinopathy and inferior retinal detachment in both eyes (Figure $2 \mathrm{~A}$ and B). Drug toxicity was suspected. We told the patient and her family to stop Otrivine. While we were about elaborated on the findings and management, the mother of our patient looked doubtful.Thereafter, they didn't come back for follow-up and reassessement.

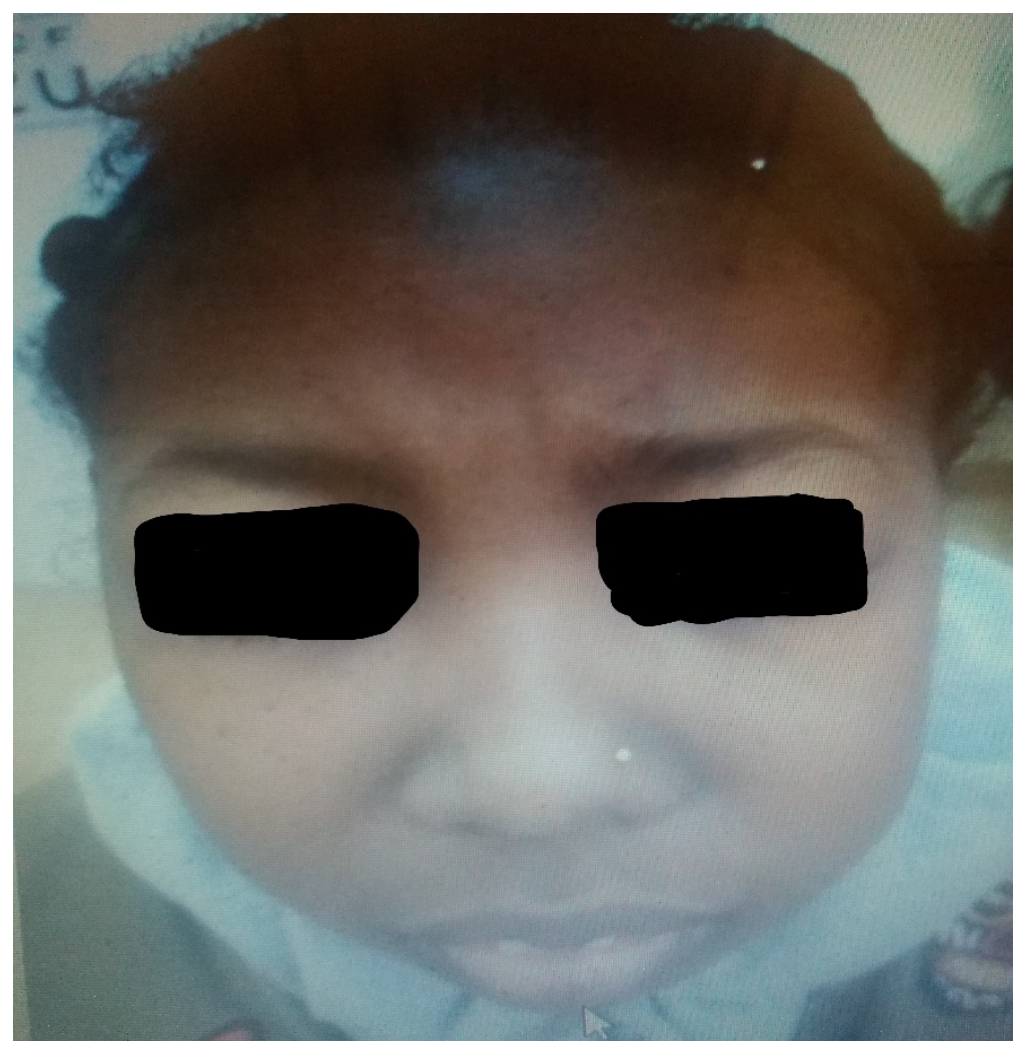

Figure 1 : Patient presenting swelling face 


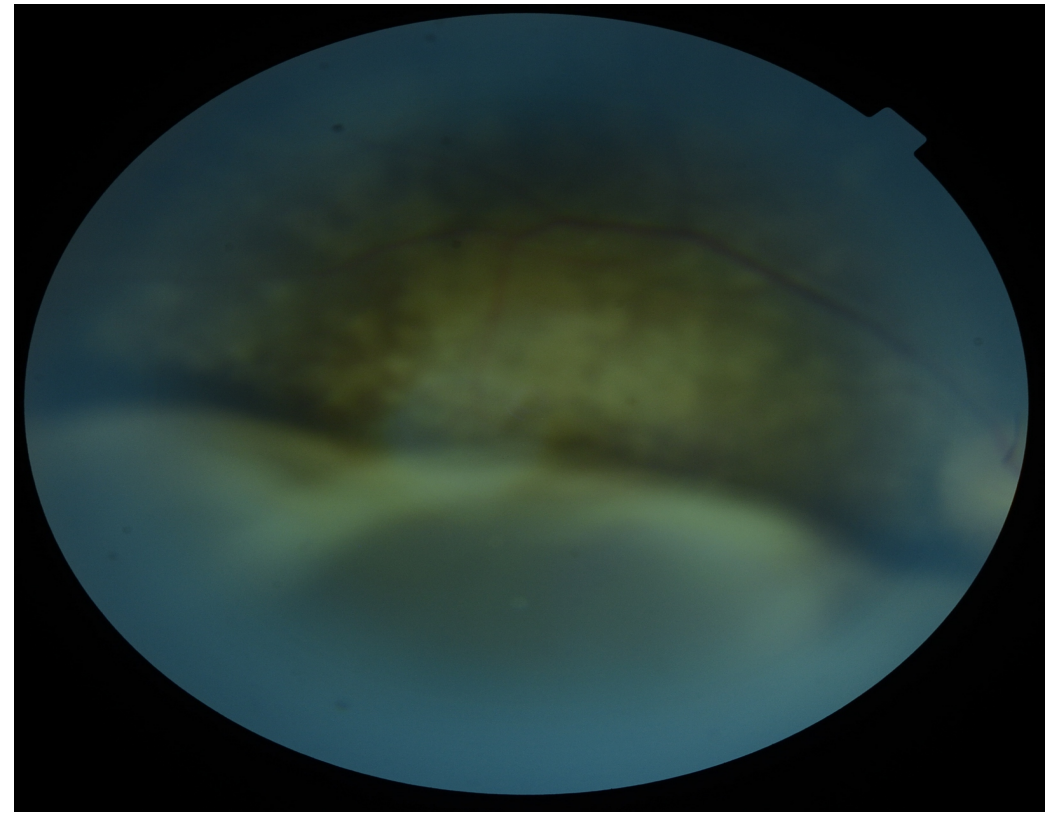

Figure 2 A : Inferior Retinal Detachment on right eye

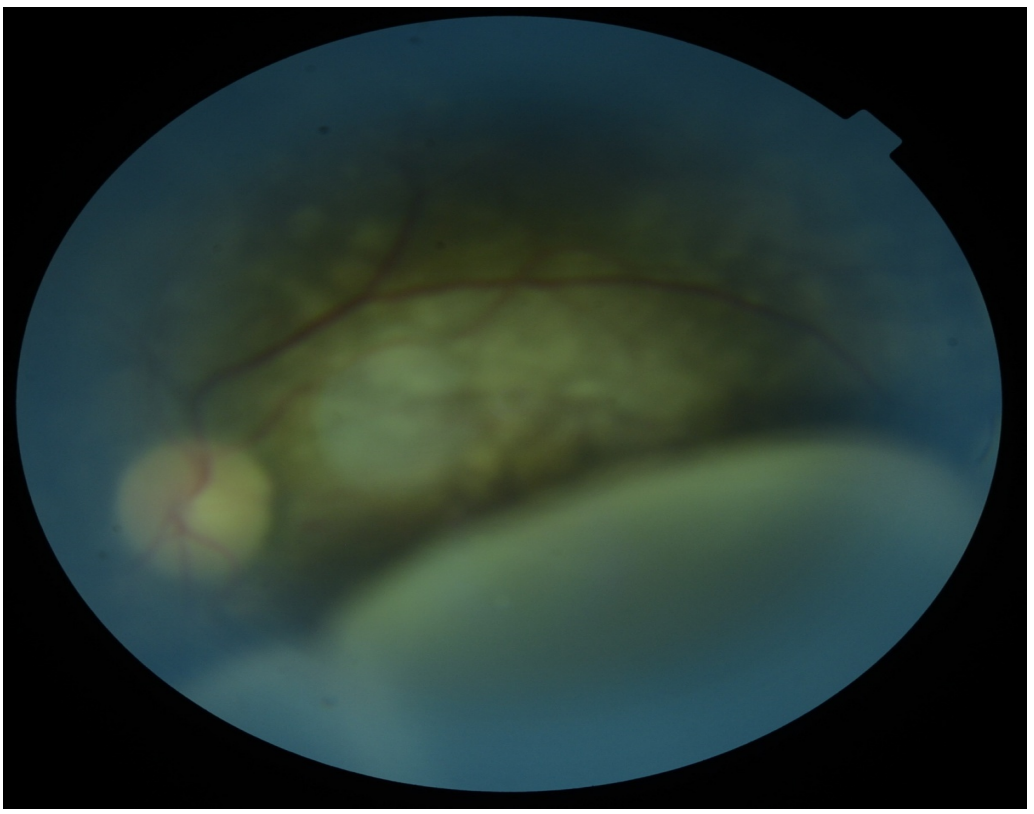

Figure 2 B : Inferior Retinal Detachment on left eye

\section{DISCUSSION}

No case of brutal bilateral retinal detachment have been reported yet during Takayasu disease or usage of Otrivine nasal spray. Trigui A and al conducted a study to evaluate the incidence of bilateral retinal detachments, to analyse the incriminated factors and anatomical and functional results after treatment. They stated that retinal detachment can be discovered in both eyes in the first consultation, in other cases, a retinal detachment can be seen in the second eye in the follow-up of the first eye. They found that many factors are incriminated in the bilateral retinal detachment like myopia, refractive surgery and degenerative disease [4].

Several studies were conducted to evaluate the ophtalmic toxicity of the vasoconstrictor drugs. The blood-retinal barrier prevents many systemically administered drugs from entering the eye via the circulatory system. Yet many medications that are administered systemically for nonocular conditions may still gain access to the eye and evoke ocular toxicological complications [5]. 
Drug-induced retinal toxicity can occur from the use of systemic, intravitreal, or topical medications. Despite the presence of the blood-ocular barrier, the retina is vulnerable to toxic effects of systemic medications leading to dysfunction and retinal degeneration.These toxicities can be categorized as damage to the retinal pigment epithelium (RPE) and photoreceptor complex, vascular damage, ganglion cell or optic nerve damage, cystoid macular edema, crystalline retinopathy, uveitis, changes in color vision and electroretinography (ERG), and other miscellaneous effects. Stephen et al $\mathrm{H}$ reported that Corticosteroid induce a serous macular detachment [6]. There are also reports which indicate that long-term therapy of systemic corticosteroids causes severe, chronic and recurrent central serous chorioretinopathy (CSC) and occasionally exudative retinal detachment which may lead to vision loss [7][8].

Our patient took both corticosteroid and Otrivine. We have no clear-cut-evidence proving drug-induced retinal detachment. So, our patient have been taking corticosteroid since october 2018, why the retinal detachment suddenly appeared after about 8 months of treatment?

As far as Otrivine Adult Nasal Spray is concerned, it is used for application in the nose to give relief from nasal congestion (blocked nose, including colds) perennial and allergic.Otrivine Adult Nasal Spray contains the active ingredient xylometazoline hydrochloride that constricts nasal blood vessels and increases nasal airflow, enabling patients with a blocked nose to breathe more easily.Otrivine adult nasal Spray can cause side effects, although not everybody gets them. Occasionally the following side effects have been reported: A burning sensation in the nose and throat, local irritation, nausea, headache, dryness of the nasal membranes, temporary and passing visual disturbances, allergic reactions, cardiovascular effects, for example, palpitations may also occur especially if the patient have heart problems [9].

Morris and colleagues, reported in their study a rebound congestion at 3 days after treatment initiation with Xylometazoline [10]. Our patient presented nasal congestion, dry mouth, swelling of the face and lips only 2 day after the starting of the use of Otrivine nasal spray.

Among the side effects oxymetazoline including the local decongestants outlined in the prospective literature is: increase in runny or stuffy nose, blurred vision, fast, irregular, or pounding heartbeat, headache, dizziness, drowsiness, lightheadedness, high blood pressure, nervousness, trembling, trouble in sleeping and weakness. Our patient presented a blurred vision, headache as well as hypertension. Furthermore, the systemic side-effects of use of topical oxymetazoline have been reported as event reports in the literature [11]. In a study conducted by Loewan $\mathrm{AH}$, it has been reported that the following the use of nasal spray of oxymetazoline reversible segmental cerebral vasoconstriction and severe headache has been observed in the adult women attended at the clinic. After use of sympathomimetic agents some mechanisms that are likely to be the cause of the problem in the central system (stroke) including acute hypertension, vasospasm, thrombosis, and angitis induced vasospasm have also been reported. In addition, the patients using sympathomimetic local and/or systemic medications should be asked about the sudden heavy headaches [12].

Ayse I and colleagues conducted a research to investigate the potential effects of chronic exposure to a nasal decongestant and its excipients on ocular tissues using an experimental rat model. Epithelial defects and dry eye were common findings in all study groups. Cataracts developed in two cases clinically. Histopathological evaluation revealed many different pathological alterations in all parts of the ocular tissues such as corneal edema, polypoid proliferation and hyalinization of the vessel wall, cystic formation of the lens, retinal nerve fiber layer degeneration, and corpora amylacea formation of the lacrimal gland. They outlined that prolonged usage of the nasal decongestant xylometazoline and its excipients may cause 
ophthalmic problems such as dry eyes, corneal edema, cataracts, retinal nerve fiber layer, and vascular damage in rats. In our case, the anterior segment was normal, there was no cataract. They suggested that ophthalmologists should keep in mind the potential ophthalmic adverse effects of this and exercise caution with drugs containing xylometazoline [13]. Several reports have linked sympathomimetic drugs with ocular damage. Mondal and al described a 43-yearold man who developed blurred vision, metamorphopsia, and paracentral scotoma with xylometazoline [14]. Moreover, Buysschaert et al. described a 34-year-old male who used xylometazoline every $3 \mathrm{~h}$ in the last 2 years for nasal congestion and presented with blurred vision associated with headach due to papilloedema and hypertensive retinopathy. The blood pressure was 210/120 $\mathrm{mmHg}$ [15]. But none of them affirmed to obesrve retinal detachment and swelling face. It's similar to our case, our patient had 195/11 mmHg blood pressure, blurred vision and headache. Hafidi $\mathrm{Z}$ et al reported a case of 24-year-old pregnant woman presenting bilateral exudative retinal detachment. On examination, the visual acuity of the patient in both eyes was perception of hand movement. The fundus examination observed multiple bullous retinal detachment, some hemorrhage and coton wool nodes. They diagnosed an exsudatif retinal detachment in the context of hypertension during eclampsia [16]. Conversely, our patient presented a bilateral retinal detachment without papilloedema. Buysschaert et al highlited that Xylometazoline is an imidazoline-derived alpha-2 agonist available over the counter as long-acting topical nasal decongestant.Short-term use causes vasoconstriction and reduces congestion. However, long-term use can result in rebound nasal congestion and the vicious circle of rhinitis medicamentosa. Although short-term use of topical alpha-2 agonists has no systemic toxicity, long-term abuse has been reported to cause systemic vasoconstriction and severe cardiovascular complications [15]. But our patient had symptomes evoking congestion rebound only 2 days after the usage of Otrivine.

In a study conducted by Loewan $\mathrm{AH}$ et al, it has been reported that the following the use of nasal spray of oxymetazoline reversible segmental cerebral vasoconstriction and severe headache has been observed in the adult women attended at the clinic. After use of sympathomimetic agents some mechanisms that are likely to be the cause of the problem in the central system (stroke) including acute hypertension, vasospasm, thrombosis, and angitis induced vasospasm have also been reported. In addition, the patients using sympathomimetic local and/or systemic medications should be asked about the sudden heavy headaches [12].

Apart from ophtalmic involvement, there are two reports of psychiatric syndromes associated with the sympathomimetic agent oxymetazoline administered by nasal spray: first, Soderman $\mathrm{P}$ et al reported adverse reactions in the central nervous system such as convulsions, excitation, insomnia, sedation and visual hallucinations in five infants who received regular doses of the drug [17], and Blackwood GW described a delirious state with acute paranoid symptoms in a 41-year-old woman who abused oxymetazoline.In general, sympathomimetics cause hypertension, tachycardia, peripheral vasoconstriction and common cause systemic toxicity. Like this, our patient had tachycardia and hypertension [17] [18].

Few cases and studies related to the effects of other vasoconstrictors on the eye were published.

C Ozturkmen report a case of 9-year-old female patient presented of visual loss in both eyes for the past day after receiving symptomatic for upper respiratory tract infections... A large bilateral serous elevation of the macula was observed in both eyes after abuse of pseudoephedrine $60 \mathrm{mg}$ [19]. Thus, a vasoconstrictor pseudoephedrine could cause serous macular detachment, why Oxylometazoline a vasoconstrictor as well could not? 
Ovet et al administered $60 \mathrm{mg}$ of PSE orally in subjects and measured the choroidal thickness of the right eyes at the first, third, and sixth hours in a study on a group of 50 healthy patients. They reported that choroidal thickness increased at the first hour and returned to normal at the 3rd hour. Cem 0 and Mustafa B thought that increased resistance in the choroidal vessels due to Pseudoephedrine's vasoconstrictive effects and consequent deterioration of the bloodretina barrier function of the retinal pigment epithelium followed by fluid passage into the subretinal area could have been instrumental in serous macular detachment development as a result of pseudoephedrine toxicity [20]. The same, Michael et al reported central serous chorioretinopathy in one eye each of a 43-year-old female and a 32-year-old male who were using high doses of pseudoephedrine. Like these, otrivine used by our patient is a vasoconstrictor also that may cause retinal detachment [22].

The mechanisms by which these toxins exert their harmful effects on the eye are varied and in most cases remain poorly understood [22] [23] [24].

In man, ocular toxicity associated with systemic drug therapy can result in retinal degeneration, although it most frequently comprises visual disturbances including decreased visual acuity, impaired color perception, visual field defects, scotomata, night blindness, visual perseveration beyond the physiological afterimage (palinopsia), and an illusory movement of the physical environment (oscillopsia)[23].

All drugs used in the treatment of ocular and systemic disorders have the potential to induce ad verse effects in the eye. They can cause specific and non-specific abnormalities of various ocular structures that may manifest as blepharokeratoconjunctival disorders, glaucoma, cataract, uveal tract disorders, retinopathy and optic neuropathy. The extent and severity of ocular toxic adverse effects are often related to duration of treatment dose and individual patient susceptibility [25].

The untoward effects of drugs are typically bilateral and oftenly neglected. The retinal toxical involvement depends on several parameters : integrity or alteration of blood-retinal barrier, the degre of hydrophobicity of molecules to pass through the bloo-retinal barrier, the dose and the duration of the treatments, existence of silver or renal failure limiting the elimination or genetic predisposition. Like this, our patient has kidney failure to explaine the delay of the excretion of the drug [26].

We suspected that our patient overused the Otrivine because it was a self-medication. It is reported that according to a survey conducted in Madagascar, prescription and over the counter medication can be bought from illegal pharmacies and street sellers as well as sometimes from legal pharmacies without a prescription. Many people may go to the doctor the first time for a particular illness but when it reappears, simply buy the same medication in the street and repeat the same dosage or copy what they have seen other people doing [27]. This fact is similar to the case of our patient whose Otrivine was bought without medical prescription and she had already used Otrivine before. Buying medicine in the street or illegal pharmacy means one can buy individual tablets unlike in a pharmacy or hospital where you need to buy the whole course of treatment. Self-medication may mean taking the wrong medication, the wrong dosage or not taking the full course. Location and ease, as well as money, are the reasons for high rates of self-medication and it is incredibly common with almost $90 \%$ of survey [28]

Furthermore, they didn't return for follow up, the mother of our patient probably brought her daughter to traditional healer because she thought that it was an witchcraft act to cause the 
sudden blindness of her daughter. In Madagascar, Many illnesses are understood in a culturally determined way, symptoms which can be explain by certain practices, foods, the weather or spirits. These often involve visiting a traditional healer for this or other treatment. This may result in delays to seeking appropriate care [27]. Besides, Mary Danielli reinforced in their study that according to some malagasy people culture, the witches cause sickness, death and injury. Moreover, witches poison people through food, by thrusting poisoned fingers in the mouths of travellers waylaid at night and so forth. There are the members of the cult whose profession is in association with the spirits of the ancestors, to cause death and destruction [29].

Blackwood GW suggested that physicians should enquire about the overuse of nasal sprays in patients with psychosis. They must monitor patients' use of nasal sprays containing oxymetazoline and advise those with chronic nasal congestion that the overuse of this drug may be dangerous. Finally, physicians should be aware of the dangers of all commonly used products that contain sympathomimetic drugs [16].

\section{CONCLUSION}

In conclusion, both corticosteroid and vasoconstrictor drugs may reportedly cause retinal detachment. We found to our patient all possible side effects of Otrivine such as headache, hypertension, swelling face, buccal an nasal congestion, blurred vision and palpitation. The relation between the history of the intake of Otrivine spray had a close link to the occurrence of the aformentioned symptoms. Some researches evoked retinal detachment during hypertension and during the use of vasoconstrictors.These abovementioned theories might be enough to back up our opinion in which bilateral exsudative retinal might be triggered by Otrivine. If it were corticosteroid-induced, the symptoms would have happen earlier. However, We ask several experts for their opinion toward this case.

\section{References}

Steinberg RH, Wood I. Pigment epithelial cell ensheathment of cone outer segments in the retina of the domestic cat. Proc R Soc Lond 1974; B.187: 461-78.

Kang HK, Luff AJ; Management of retinal detachment: a guide for non-ophthalmologists. BMJ. 2008 May 31;336(7655):1235-40.

Gariano RF, Chane-Hee K; Evaluation and Management of Suspected Retinal Detachment. Am Fam Physician. 2004 Apr 1;69(7):1691-9.

Trigui A, Khadi N, Ghorbel I, Fekik J. Les décollements de rétine bilateraux. J.I.M.Sfax.2005;1(10) :23-6. Disponible sur: http://www.medecinesfax.org>article06-9-10.pdf.

Zinn, K, Greenseid, D. Toxicology of the retinal pigment epithelium. Int Ophthalmol Clin 1975 ; 15, 147-58.

Stephen H. Tsang and Tarun Sharma. Drug-Induced Retinal Toxicity . AEMB, volume 1085 ;Atlas of Inherited Retinal Diseases; Chapter 48.

Schwartz SG, Grysbowski A, Wasinska-Borowiec W, Flynn HW, Mieler WF. Update on pharmacologic retinal vascular toxicity. Curr Pharm Des 2015;21:4694-7.

Meier-R, Meier-Ruge. Morphology of experimental chloroquine retinopathy in the rabbit. Ophthalmologica 1973 ; 150: $127-37$.

Otrivine. Active substance(s): Xylometazoline Hydrochloride available online https://www.drugs.com/uk/otrivine-adult-nasal-spray-leaflet.html

Morris S, Eccles R, Martez SJ, et al. An evaluation of nasal response following different treatment regimens of oxymetazoline with reference to rebound congestion.Am J Rhinol 1997;11:109-15.

Recep D, Hasan G, Mustafa S, Fatih S, Zeynel Abidin T et al. Systemic side effects of locally used oxymetazoline . Int J Clin Exp Med 2015;8(2):2674-8 
Loewen AH, Hudon ME and Hill MD. Thunderclap headache and reversible segmental cerebral vasoconstriction associated with use of oxymetazoline nasal spray. CMAJ 2004; 171: 593-94.

Ayse Ipek Akyuz Unsal1, Yesim Basal2, Serap Birincioglu3, Tolga Kocaturk1, Harun Cakmak1, Alparslan Unsal4, Gizem Cakiroz5, Nüket Eliyatkın6, Ozden Yukselen7, Buket Demirci5.0phthalmic adverse effects of nasal decongestants on an experimental rat model. Arq Bras Oftalmol. 2018;81(1):53-8.

Mondal L, Basu S, Baıdya K, Bhaduri G. Central serous chorioretinopathy after dacryocystorhinostomy operation on the same side.Indian J Ophthalmol. 2009;57(1):57-8.

Buysschaert I, Van DJ, Dujardin K. Hypertensive crisis and end-organ damage induced by over-the-counter nasal decongestant abuse. Eur Heart J. 2011;32(24):3114.

Hafidi Z, Handor H , Oudanane S,Laghmari M, Derrar R, Sabrane I et al.Décollement exsudatif bilatéralde la rétine révélant une toxémie gravidique. J fr ophtalmol (2014) ; 37 :65-6

Soderman P: Nose drops can induce cerebral reactions in children.Latartidmingen 1983; 80: $3286-7$.

Blackwood GW: Severe psychological disturbance resulting from abuse of nasal decongestants. Scott Med J 1982; 27: $175-6$.

Cem Ozturkmen, Mustafa Berhuni, Pediatric Case with acute bilateral serous macular detachment. Korean J Ophthalmol 2019;33(2):196-197 https://doi.org/10.3341/kjo.2018.0067 .

Ovet G, Alpfidan I, Sakarya Y, et al. The acute effect of pseudoephedrine on choroidal thickness. Clin Ter 2016;167:63-6.

Michael JC, Pak J, Pulido J, de Venecia G. Central serous chorioretinopathy associated with administration of sympathomimetic agents. Am J Ophthalmol 2003;136:182-5.

Loo JL, Lee SY, Ang CL. Can long-term corticosteriods lead to blindness? A case series of central serous chorioretinopathy induced by corticosteroids. Ann Acad Med Singapore. 2006; 35(7):496-9.

Scroggs, MW, Klintworth, GK . Drugs and toxins. In: Pathobiology of Ocular Disease. New York, 1994 pp. $1163-88$. LARS M , ULRICH S. An Overview on the Toxic Morphological Changes in the Retinal Pigment Epithelium after Systemic Compound Administration. Toxicologic Pathology 2007 ; 35:252-267, 2007.DOI:

10.1080/01926230601178199

Junping L, Ramesh C. Tripathi3 and Brenda J. Tripathi3,4 Drug-Induced Ocular Disorders. Drug Safety $2008 ; 31$ (2): 127-41.

Faure, I. Audo, Iatrogénie oculaire des médicaments systémiquesC. EMC. 2016.

Jessica L Morris. Assessment of Maternal and Child Health in Fort Dauphin, Madagascar. SEED Madagascar. Novembre 2011 Novembre 2012.

Banque mondiale. Les indicateurs du développement dans le monde.Disponible en ligne sur https://databank.banquemondiale.org/source/world-development-indicators

Mary Danielli (1947) . The Witches of Madagascar: A Theory of the Function of Witches and of their Organization Based on Observations of an Existing Cult, Folklore, 1947 ; 58(2) : 261-76, DOI:

10.1080/0015587X.1947.9717852 